\title{
Introduction
}

Nearly five years have passed since I wrote Rebuilding Trust in Banks: The Role of Leadership and Governance, focusing on the problems of governance in banks and what could be done about them. Eight years have passed since I wrote Challenges in Implementing Corporate Governance: Whose Business is it Anyway? which dealt with issues faced by publicly listed companies in general. Since 2008 I have led workshops and training programs for more than 1,500 directors, where I have come to appreciate better the dilemmas faced by independent nonexecutive directors as they try to fulfill their fiduciary duty.

These dilemmas have become much more challenging as the context of corporate governance widened from considering how best to deliver shareholder value in a publicly listed enterprise from a legal and accounting perspective in terms of compliance-its primary focus in 1992 when the Cadbury Report was published-to including ethics; reconciling stakeholder expectations and issues of public governance.

Annual reporting requirements have also become more demanding, as listed companies were required to add social and governance reporting sections covering ESG issues in annual reports; and then to adopt integrated reporting to provide greater transparency for investors and analysts. Regulators at first were satisfied with a "comply or explain" approach to adopting best practices outlined in the various codes of corporate governance. When they realized how this was abused by companies adopting third party "cut and paste" generalities in the governance section of the annual report, some regulators, now require listed companies to "apply or explain” instead.

Being an independent director in the twenty-first century has become much more onerous. First, came the changes in legislation and regulation following Enron with the passing of the Sarbanes-Oxley Act in 2002. Second, came the change in the climate of public opinion regarding boards after the Global Financial Crisis in 2008 and extending the fiduciary duty of directors of banks to include depositors and of insurance companies to include policyholders. Third, came Australian rulings in 2011 and 2012 which are regarded by Commonwealth judges as precedents to be considered or as being "persuasive" when passing judgement. These rulings set a much higher standard for the duty of care than existed previously.

As a result of undertaking third party board evaluations with face-to face in-depth interviews of board members and managers reporting to boards, I realized there are significant gaps between the understanding members of the board have of their respective roles and what regulators expect and believe should happen and what happens.

These differences in expectation are made more serious by the fact codes of corporate governance, which are voluntary, are based on a philosophy that "boards govern and direct, management manages"; whereas statute law in many Commonwealth jurisdictions stipulate that "directors manage and direct" the affairs of the businesses 
for which they are responsible. The higher standard of the duty of care, combined with what some companies acts define as the responsibility of directors, raises the need to redefine the boundaries of responsibility between boards and management.

Given these changes in the corporate governance environment over the past twenty-five years, I felt it would be useful to write a book that:

1. Explains what corporate governance is; why it matters and how its remit has changed in the past twenty-five years; revisiting the role of the board and its component parts, in the much more onerous twenty-first century context.

2. Provides directors with a "how to" guide to help them fulfill their designated six responsibilities: setting strategy, reviewing its implementation, managing risk, planning succession, ensuring internal controls, and engaging stakeholders.

3. Considers three critical areas in value creation that do not feature on company balance sheets as assets-reputation, people, and processes ${ }^{1}$ where a change in approach might help avert a "political tragedy of the commons," namely by focusing more on reputation, investing in people as assets rather than treating them as costs, and recognizing the fundamental importance of processes and harnessing them to create long-term value.

\section{Structure of the Book}

This book is presented in three parts.

\section{Part One: Anatomy of Corporate Governance}

This consists of six chapters. The first two chapters set the "conceptual" framework of corporate governance. The next four chapters explore "operational" considerations affecting boards.

Chapters 1 and 2 broaden the discussion of corporate governance from the traditional, mainly legal, and accounting, compliance-oriented approach for public listed companies, by showing how the definition has changed to cover more areas of responsibility; hence, the double meaning in the title "Better Governance Across the Board." I also highlight the fact standards to which boards and directors are now held have

1 "The two most important things in any company do not appear in its balance sheet: its reputation and its people." Henry Ford, https://www.azquotes.com/quote/1430055. It is ironic that Henry Ford did not mention "processes" when his adaptation of the Swift meat works processes created the revolutionary assembly line, so essential to much of modern manufacturing. So, I would add processes, for it is processes that differentiate "third world mindsets" from "first world mindsets." 
been raised dramatically from the 1925 definition of directors' duties to the incredibly challenging standards set by rulings in the twenty-first century, which, from my discussions, many directors have yet to recognize fully.

Chapter 1, "What Is Corporate Governance and Why It Matters" explores the principles of good governance as they apply to all enterprises regardless of whether they are listed, for-profit or not, and regardless of their ownership structure, explaining why in implementation, however, "no one size fits all" jurisdictions or companies. I define what corporate governance (CG) is and why it matters.

Chapter 2, "Integrating Ethics and Branding," introduces the idea of expanding the scope of CG beyond the limited boundaries of board responsibility set by the law and regulations. It discusses the importance of ethics and branding because these two fundamental topics seem so often to be missing from legalistic and accounting-based discussions of corporate governance. I explain why I believe business ethics are essential and go on to explore why ethics are such a difficult area. I provide a five-stage "right-good" decision-making framework, reconciling consequential, duty-based, and personalistic ethics for directors to use when making or reviewing decisions. As far as branding is concerned, I make the case corporate/organization brands are the responsibility of the board as they reflect the mission, vision and values of the enterprise-areas that are for the board to define.

Chapters 3-6 discuss the role and responsibilities of effective boards. I explain the need to define where the boundaries of responsibility lie between boards and management, as a result of differences between what voluntary codes of corporate governance recommend and what many statutory companies' acts stipulate. I then discuss what it takes to chair an effective board and be an effective board member. I conclude with three case studies where the boards failed to rein in charismatic, domineering CEOs with disastrous results.

Chapter 3, "Redefining the Boundaries of Responsibility" compares the traditional and modern views of the boundaries of responsibility between board and management. This contrasts the traditional view that boards "govern and direct" with the modern view that boards "manage and direct" and makes the case for redefining the boundaries of responsibility clearly, incorporating them into the memorandum and articles of association and board charter, if there is one.

Chapter 4, "Chairing an Effective Board" discusses the context determining different engagement styles of boards with management and explain why different styles are needed at different stages in the enterprise's life stages. This also depends on the constitution of the organization and is covered in what must be in a board charter-the document that determines the roles and responsibilities of the board, its members, and committees. I explore further the role of the chair in ensuring board dynamics and culture are appropriate to demonstrate the immense importance of the chair in ensuring board effectiveness.

Chapter 5, "Being an Effective Board Member" discusses the quite distinct roles of chair and CEO and explains why they should be separated-the norm outside the 
United States-an effective chair has a very demanding job when governing the board and is the link between the board and the CEO. An effective chair is a coach and sounding board for the CEO as well as the person who hires and fires the CEO. Conflicts of interest are inevitable if the chair and CEO are one and the same. I also explore what it takes to be an effective director and member of the board.

Chapter 6, "Reconciling Leadership and Governance" explores the role of governance in providing checks and balance to prevent successful, dynamic CEOs from abusing their executive power. Great charismatic leaders who are not subject to checks and balance will fall victim to Lord Acton's saying, "Absolute power tends to corrupt absolutely" and may destroy the businesses they lead. Governance without leadership will result in mundane performance at best. Hence, a key responsibility of boards is to reconcile leadership with governance. The chapter looks at three cases where highly successful CEOs were allowed to destroy the firms they led because of weak boards.

\section{Part Two: The "Five P” Framework and Good Governance}

This consists of seven chapters designed to act as a working "how to" guide for directors in fulfilling their six responsibilities outlined in the most up to date codes of corporate governance.

Chapter 7, “Introducing the 'Five P' Performance Framework" introduces a simple framework that directors can use for reviewing any decision brought before the board. The framework consists of five elements that must be aligned if the enterprise is to achieve its designated mission and vision. The five elements are "purpose"; "principles" or values; "power” reflecting the optimum organizational design and associated reporting relationships; "people" in terms of number of employees, competencies and character required to get the job done; and "processes"-the glue that holds everything together. Should any one of the five elements be out of alignment, the organization will fail to achieve its designated mission.

Chapters 8-13 explore how directors can operationalize their six corporate governance responsibilities. They deal in turn with setting strategy, reviewing its implementation, managing risk, planning succession and managing talent, ensuring internal controls, and engaging stakeholders.

Chapter 8, "Setting Strategy" argues it is the responsibility of boards to set strategic direction rather than acting as rubber stamps signing off on what management proposes. Initiating strategy is the primary responsibility of the board, even though in practice most boards are reactive/passive responding to whatever management puts in front of them. It is a fundamental premise of this book that determining and defining strategic direction and priorities is the responsibility of the board and it is the responsibility of the CEO and management to deliver the board-agreed strategic objectives. 
Chapter 9, "Reviewing Strategy" explores the five-stage review process for setting strategy, defining the metrics that matter. It examines the financial metrics and categorizes them as metrics for investment and metrics for ongoing operations. It discusses the deficiencies of financial metrics and explores how to include the "voice of the customer" recognizing there are four archetypical customer segments. It discusses the components that make up market share and includes the soft nonfinancial metrics and key performance indicators (KPIs) boards must look at. It shows how the "Five P" framework can be applied to evaluate whether anything has been missed.

Chapter 10, "Managing Risk" discusses the board's role in risk management, dividing risk into three categories: "cultural risks," "traditional risks," and "earnings driver risks." It defines risk and focuses on cultural risks because research suggests these are rarely covered by boards, yet they are often the most material risks. It also explores systemic risks, which are a relatively new area for boards to consider, as a result of the lessons learned in the Global Financial Crisis, where boards also learned to their cost to pay attention to KPI risk and CEO risk. It shows how the "Five P" framework can be applied to evaluate whether anything has been missed.

Chapter 11, "Planning Succession; Managing Talent" discusses succession planning and talent management. It begins by exploring how best to plan succession for the board, discussing criteria for effective directors, using directors' gap analysis in terms of their ability to contribute to board discussions across eleven knowledge and performance parameters. It then deals with CEO succession planning, the problems in recruitment and what to look for in today's CEO. Based on research by INSEAD it argues that effective CEOs today are "chief enabling officers" rather than the traditional "chief executive officers" and explores the seven attributes of such CEOs and how such CEOs behave in times of crisis. It explores the issues surrounding CEO remuneration and discusses the merits of a number of alternative approaches.

It covers four steps in talent management and introduces the concept of feasibility feedback-relating gaps in organizational design and personal development plans to the ability of the organization to achieve the desired business strategy. It shows how the "Five P" framework can be applied to evaluate whether anything has been missed.

Chapter 12, "Ensuring Internal Controls" deals with internal controls. The chapter begins by comparing the three lines of defense and five lines of assurance philosophies. It goes on to look at what matters in the numbers and the seven areas in financial reporting directors must dig into to understand what is really happening if they are to meet the twenty-first century standard for the duty of care. Given the increasing penalties for noncompliance, the chapter explores six practices directors should consider adopting for the audit committee to have effective control. It then briefly

2 Booz Allen \& Hamilton (2004), “Too Much SOX Can Kill You: Resolving the Compliance Paradox.” 
discusses the COSO approach to enterprise risk management. It shows how the "Five P" framework can be applied to evaluate whether anything has been missed.

Chapter 13, "Engaging Stakeholders" discusses stakeholder engagement. This is an area most boards do not spend enough time on. The chapter begins by reminding boards there are other ways stakeholders can penalize bad practices than what investors choose to do, which tends to be the focus of much of the discussions on stakeholder engagement. It then looks at shareholder-driven market discipline, stakeholder-driven market discipline, and regulatory-driven stakeholder engagement. Stakeholders are defined as primary, secondary, and tertiary and their likely impact on the organization is discussed. The three objectives of stakeholder engagement are reviewed: building trust, soliciting support, and creating goodwill. The chapter covers the need to communicate the "ends" of the organization and appropriate time horizons so investors understand what the organization is trying to do. It then deals with the process of effective stakeholder engagement-categorizing stakeholders as advocates, supporters, spectators, saboteurs, and adversaries and discussing how best to deal with each.

Finally, the chapter deals with ways of communicating effectively, discussing the chain of command, the different roles of investor relations and PR, and the need to adhere to the six principles of effective communication.

\section{Part Three: Creating Value Through Reputation, People, and Processes}

The three most important contributors to long-term competitive advantage, the three most important assets any enterprise has are its reputation, people, and processes. However, they do not feature on the balance sheet and so are often undervalued or forgotten. Three chapters explore what boards could do differently to create sustainable long-term value provided they give reputation, people, and processes the attention they deserve. They also explore the issue of a "political tragedy of the commons" caused by individual boards focusing on doing what is best for their own organization at the expense of the environment, community, and economy, if all boards were to follow suit.

Chapter 14, "Focusing on Reputation" discusses the need for boards to focus on it when making decisions, particularly now more than $80 \%$ of the value of companies is intangible and directors have come to recognize reputation risk is their number one risk. It shows five ways a good reputation improves business and explores its role in setting strategy: defining a sustainable mission, creating a compelling vision, and reconciling value creation and extraction. It discusses how best to minimize reputation risk across the company value chain looking at vulnerabilities in the areas of "natural," "social" and "human" capital; in other words, at the sources of reputation risk in the environmental, social, and workplace practices of the company and how to mitigate them. 
Chapter 15, "Investing in People" begins by exploring the paradox that directors regularly say people are assets but treat them as costs. This is because the financials only record people as payroll costs in the income statement and do not show them as assets on the balance sheet. As a result, boards seek to minimize and externalize the costs of people. Employers who offer "psychic" income (vocations and fashion) also underpay, justifying their actions on the grounds of the "psychic income" they offer. As a result of thinking of people as costs, boards tend to treat people as being disposable, especially in Anglosphere economies. This leads to low loyalty and lack of investment in long-term training and long-term relationships, which have been developed successfully by "Rhenish capitalist" economies. This in turn has led to more successful economies and better jobs for the middle- and lower-income groups than has been true of the United States and the United Kingdom. The chapter then goes on to discuss how best to invest in people by recognizing there are four different types of leadership. It argues HR should stop trying to fit "square pegs into round holes," ignoring the importance of default personalities, which make people suited for jobs requiring their default personality. It also makes the case for having two career ladders-a managerial ladder and a technical ladder-in recognition of the fact most people do not want to manage other people.

Chapter 16, "Harnessing Processes to Create Long-Term Value" looks at how boards can use processes differently to create long-term value, recognizing the importance of an external "CG ecosystem" to support their efforts. The chapter begins by recognizing why boards fail and suggests six process changes to help them do better: using "rotating Devil's Advocacy" to create constructive challenge in the boardroom; adopting activity-based costing to understand the true sources of profitability; reframing budget and cost control decisions; setting KPIs and targets using a ten-step process; adopting a systematic and effective innovation process; and last and perhaps most important, recruiting more women to boards.

The chapter then explores what is needed outside companies to reinforce their efforts at good governance. It describes an effective "CG ecosystem" consisting of four factors: effective regulation-IOSCO best practice; professional boards-supported by mandatory training and a qualified roster of directors from whom to choose; professional capital market intermediaries; and educated, financially literate investors. These four factors in turn need to be supported by good public governance; a judiciary that understands commercial law unafraid of enforcing the law, including custodial sentences; and educated investigative business journalists that follow the money wherever it leads, supported by professional external auditors to ensure accurate and timely financial reporting. 
